A trajetória da cidadania alimentar no Brasil (1993 - 2013). Machado, Rocha \& Campos.

SEGURANCA

alimentar e nutricional

\title{
Dos movimentos sociais à implementação do Programa Fome Zero (1993 - 2013): a trajetória da cidadania alimentar no Brasil (20 anos da ação da cidadania e 10 anos do Programa Fome Zero)
}

\author{
Moisés Machadoํㅡㄹ Daniete Fernandes Rocha ${ }^{2}$ e Mauro Macedo Campos ${ }^{3}$
}

\begin{abstract}
O objetivo deste artigo é analisar, com base na vertente teórica do novo institucionalismo histórico, a trajetória da segurança alimentar no Brasil, na perspectiva da cidadania, desde sua entrada para a agenda nacional até sua institucionalização como política pública no âmbito do Programa Fome Zero. Sem pretensões analíticas mais detalhadas, no que se refere aos estudos dos desenhos dos programas, a proposta do artigo é trazer, de forma sintética e ordenada, um entendimento sobre as ações que constituíram os modos peculiares de enfrentamento dos desafios da segurança alimentar no país. A garantia de uma segurança alimentar como direito social, ao contrário de outros direitos sociais concedidos aos brasileiros no passado, principalmente em governos autoritários, foi resultado da luta de movimentos sociais e reivindicações em favor da ética na política (após o impedimento do Presidente Collor, em 1992), a favor da vida e contra a fome. A institucionalização do Programa Fome Zero, junto com outros determinantes, trouxe melhoria para as condições de vida dos brasileiros mais pobres, considerando-se, entre outros, os aspectos de transferência consistente de renda para esses grupos.
\end{abstract}

Palavras-chave: Cidadania, Segurança alimentar, Política pública.

From the social movements to the implementation of the Programa Fome Zero

$$
\begin{aligned}
& \text { (1993-2013): the trajectory of food citizenship in Brazil (20 years of the } \\
& \text { citizenship action and } 10 \text { year of the Programa Fome Zero) }
\end{aligned}
$$

The aim of this article is to analyze, taking the new historical institutionalism as the theoretical basis, the trajectory of food security in Brazil, from the perspective of citizenship, since its entry into the national agenda until its institutionalization as public policy within the Zero Hunger Program. Without more detailed analytical claims, with regard to studies of the drawings of the programs, the purpose of the article is to bring in a synthetic and ordered fashion, an understanding of the actions that were the peculiar ways of addressing the challenges of food security in the country. Ensuring food security as a social right, contrarily to other social rights granted to Brazilians in the past, mainly in authoritarian governments, was the result of the struggle of social movements and claims in favour of ethics in politics (after the impediment of President Collor, in 1992), in favour of life and against hunger. The institutionalization of the Zero Hunger Program, along with other determinants, brought improvement to the living conditions of the poorest Brazilians, considering, among others, aspects of consistent transfer of income for these groups.

Key-words: Citizenship, Food security, Public policy.

\footnotetext{
${ }^{1}$ Doutorando em Sociologia Política pela Universidade Estadual do Norte Fluminense Darcy Ribeiro (UENF). Correspondência: Av. Alberto Lamego, 2000, Parque Califórnia, CEP: 28035-200, Campos dos Goytacazes (RJ). Telefone: (22) 2724-1350. E-mail: moisesm@oi.com.br

${ }^{2}$ Doutora em Sociologia pela UFMG. Professora da Faculdade de Estudos Administrativos de Minas Gerais (FEAD). Correspondência: Rua Otílio Macedo, 12 - Olhos D'água, CEP: 30.390-200, Belo Horizonte (MG). Telefone: (31) 40090987. E-mail: daniete.rocha@fead.br.

${ }^{3}$ Doutor em Ciência Política pela UFMG. Professor da Universidade Estadual do Norte Fluminense Darcy Ribeiro (UENF). Correspondência: Av. Alberto Lamego, 2000,

Parque Califórnia, CEP: 28035-200, Campos dos Goytacazes (RJ). Telefone: (22) 2724-1350.E-mail: mauromcampos@yahoo.com.br.
} 


\section{INTRODUÇÃO}

Este artigo tem como proposta analisar a trajetória histórica da Segurança Alimentar e Nutricional (SAN) no Brasil, fixando-se no período que vai de 1993 até 2013, abrangendo sua entrada para a agenda política, sua formulação como política pública e sua implementação no âmbito do Programa Fome Zero. Ressalte-se que, a partir de 2010, a alimentação passou a ser garantida na Constituição Brasileira como um direito social, tanto quanto os direitos à saúde, educação e assistência social. Daí poder-se falar de cidadania alimentar, partindo do conceito de Thomas Marshall, que define a "cidadania" como sendo um título de direitos que cada cidadão possui, ou seja, "um status concedido àqueles que são membros integrais de uma comunidade. Todos que possuem status são iguais com respeito aos direitos e obrigações pertinentes ao status."[1](p.76)4.

No Brasil, o problema da insegurança alimentar esteve historicamente presente na vida de grande parte dos brasileiros, nem tanto por falta de alimentos, mas, sobretudo, por falta de condições de acesso, ou seja, de renda suficiente para adquiri-los.

Em termos teóricos, a discussão que ora se apresenta apóia-se na vertente teórica do institucionalismo histórico. Segundo Paul Pierson ${ }^{[2,3]}$, um de seus representantes, o institucionalismo histórico busca elucidar o papel que a institucionalização das políticas públicas ${ }^{5}$ desempenha na determinação de resultados sociais e políticos efetivos. Essa vertente teórica argumenta que as políticas públicas causam efeitos no processo político ao criar, estruturar e dar espaço à vocalização de interesses. Para entender esse processo é necessário investigar a implementação das ações e programas que compõem as políticas públicas, de tal modo que seu sucesso ou fracasso pode ser compreendido, pela análise de sua trajetória no tempo. A estrutura institucional criada na implantação e na implementação das políticas públicas, para dar-lhes forma e operacionalidade, cria regras que passam a ser importantes fontes de estímulos ou de restrições a determinados comportamentos e recorrências. Estruturas institucionais geradas por políticas públicas e os atores envolvidos criam, sólidas redes em torno de determinadas ações, o que faz com que essas políticas tendam a ter chances maiores de se perpetuar. Desta forma, impõe-se resgatar a trajetória histórica da política de Segurança Alimentar e Nutricional (SAN), como uma maneira de analisar o papel dos grupos de interesse e beneficiários, que vão se constituindo na medida em que a política vem sendo construída.

Essa vertente teórica defende que a institucionalização das políticas públicas faz com que elas tenham efeito na política (enquanto disputa de poder), no sentido de que, ao se instituir formalmente (por leis, regulamentos, regimentos etc.), beneficia ou constrange o comportamento dos públicos a que se direciona. Ao serem criadas formalmente, as políticas públicas garantem recursos materiais aos atores que beneficia, fazendo, por um lado, com que esses benefícios sejam garantidos legalmente e, por outro, com que tais atores sociais passem a apoiá-las e sustentá-las, concorrendo para sua continuidade. Desta forma, a institucionalização legal de um direito não é neutra, ela tem efeitos na realidade política, pois pode garantir ou constranger o comportamento do público envolvido.

A garantia dos direitos dos cidadãos, formalmente institucionalizada em lei, pode significar que esta tenha efeitos materiais na sua vida, no seu bem estar. Assim, pode-se dizer que a evolução da cidadania, em seus aspectos de direitos civis, políticos e sociais, é também a história da afirmação jurídica desses direitos, em leis ordinárias ou constitucionais dos países. Criar um direito legal, como, por exemplo, o direito à saúde, implica não só sua institucionalização em lei, como, também, a disponibilização dos mecanismos e instrumentos necessários à sua operacionalização - infraestrutura, recursos financeiros e de pessoal. $\mathrm{O}$ mesmo ocorre com o direito à alimentação, em quantidade, qualidade e preço justo. Esse direito se configura em uma política pública de caráter transversal a muitas outras políticas. E é pensando na configuração dessa política, que se propõe, neste artigo, debater esse

${ }^{4}$ Tal título ou status é classificado, segundo Marshall[1], em três tipos de direitos: direitos civis, direitos políticos e direitos sociais, que foram sendo conquistados no decorrer dos séculos XVIII, XIX e XX. Os direitos civis são aqueles necessários à liberdade individual, de ir e vir, de imprensa, de religião, de propriedade etc. São direitos dispostos em leis e são defendidos por tribunais de justiça. Os direitos políticos garantem a participação na vida política, seja como representante (de um organismo, partido ou instituição) ou como eleitor destes representantes. Estes direitos são assegurados por normas legais dos cidadãos se associarem, de constituírem e participarem de partidos, do Parlamento e de outros espaços representativos. Os direitos sociais são aqueles relacionados ao estado de bem estar social, que abrangem o direito mínimo de bem-estar econômico (trabalho, remuneração compensatória), de segurança pública, de participação nos frutos do desenvolvimento econômico por meio de mecanismos de seguridade social (saúde, previdência, educação etc.).

${ }^{5}$ Neste artigo adotamos o conceito de política pública definido por Meny e Thoening ${ }^{[4]}$, como uma ação resultante de uma autoridade investida de poder público e de legitimidade governamental, em um espaço geográfico ou um setor específico (um país, um estado, uma cidade ou um setor como, por exemplo, a política agrícola, a saúde, a educação, entre outros). Desta forma, uma política pública pode ser caracterizada pelas ações de uma autoridade pública frente a um problema ou a um setor específico relevante, e pode ser reconhecida ou estudada através de documentos, regulamentos, leis, organogramas, orçamentos etc. 
tema, resgatando as iniciativas, ao longo do tempo, que desembocaram no que temos, nos dias atuais, como política de SAN.

Antes de analisar essa trajetória da cidadania alimentar, será elaborado um breve resumo da evolução dos direitos civis, políticos e sociais no Brasil, desde 1930, de modo a identificar ações decorrentes do Estado que insiram a questão da segurança alimentar como um elemento vinculado à cidadania. A seguir será apresentada uma discussão sobre a Política Pública de Segurança Alimentar e sua evolução no Brasil até a instituição e implementação da atual política de SAN. A título de conclusão, será realizada uma análise dos principais elementos constitutivos da atual política de SAN em contraponto a alguns indicadores da situação de segurança alimentar da população brasileira.

\section{EVOLUÇÃO DOS DIREITOS CIVIS, POLÍTICOS E SOCIAIS NO BRASIL}

No que se refere ao escopo de construção da cidadania em nosso país, é possível perceber, na evolução das políticas de bem estar, algo completamente inverso ao que Marshall[1] interpretou em relação à trajetória da construção da cidadania na Inglaterra. Naquele país aconteceu, segundo o autor, uma geração cronológica e sucessiva de direitos, que começou com os direitos civis, ampliou-se para os direitos políticos e avançou para a garantia dos direitos sociais ${ }^{6}$.

No Brasil, pode-se dizer que essa ordem foi invertida. Os direitos sociais entraram em cena antes dos direitos políticos e civis. Os direitos sociais foram os primeiros a serem assegurados. Foram concedidos no governo de Getúlio Vargas, de 1930 a 1945. Outro período de avanço dos direitos sociais ocorreu entre 1964 a 1985, na Ditadura Militar. Nesses períodos houve uma expansão da cobertura dos direitos sociais, enquanto direitos políticos e civis foram cassados ou restringidos. Em contrapartida, nos momentos de vigência do regime democrático (1945-1964 e pós 1985) os direitos civis e políticos passam a ser assegurados e ampliados.
Os direitos sociais implementados no governo Vargas (1930 a 1945) se relacionavam com os direitos dos trabalhadores urbanos ${ }^{7}$, deixando de fora a grande massa da população, que ainda vivia no campo. Os trabalhadores rurais e os informais (autônomos), por não serem sindicalizados, estavam fora das políticas de proteção desses direitos ${ }^{8}$. No período pós Vargas, os direitos civis e os sociais até então restringidos, foram garantidos na Constituição Democrática de 1946, que somente manteve os direitos sociais conquistados no período anterior? No período do regime militar instaurado em 1964 (1964 a 1985) pode ser percebida uma ampliação, tímida, de alguns direitos sociais, com destaque para a implementação da previdência para o trabalhador rural, cujo contingente foi reduzido no rápido processo de industrialização, de urbanização e de modernização agropecuária (que resultou em favelização, baixos salários e péssimas condições de vida).

Nos dois períodos de ditadura foi consubstanciado, pelo menos no tocante aos direitos sociais, um arremedo de Estado corporativo particularista. Arremedo porque se firmou em bases estreitas, calcado que estava somente no mercado de trabalho formal e urbano, que era pouco expressivo, posto que os trabalhadores do campo e outras parcelas crescentes de mão de obra urbana não tinham assegurados seus direitos (a população expulsa do campo em decorrência da modernização da atividade agropecuária buscou as cidades, onde se empregava em trabalhos precários e informais).

Em 1985, foi eleito Tancredo Neves, primeiro presidente escolhido, ainda que por via de eleições indiretas, pós Ditadura Militar. Inicia-se, nesse momento, o mais longo período democrático que o Brasil experimentou. O coroamento desse processo de democratização teve como ponto de referência a promulgação da Constituição Federal de 1988, quando foram consideravelmente ampliados os direitos sociais, na esteira da retomada dos direitos civis e políticos a partir de 1985.

\footnotetext{
${ }^{6}$ Marshall[1] em seu clássico "Cidadania, Classe Social e Status" analisa o processo de construção da cidadania inglesa, como uma evolução de direitos. Indo dos direitos civis, passando pelos direitos políticos e desaguando nos direitos sociais. Para o autor, a construção da cidadania, parte do surgimento dos direitos civis (intimamente ligados às liberdades civis), amplia-se com a concessão dos direitos políticos, com o sufrágio eleitoral e o funcionamento do sistema partidário-eleitoral, que contribuíram para possibilitar, via demandas eleitorais deste sistema, a garantia dos direitos sociais (ou seja, de participar dos bens produzidos pela sociedade, que é uma das concepções do Welfare State). ${ }^{7}$ No período Vargas (1930 a 1945), foi criado o Ministério do Trabalho, da Indústria e do Comércio, que atuava nas áreas trabalhista, sindical e previdenciária, num corporativismo controlado pelo Estado, semelhante ao modelo corporativo implementado por Mussolini na Itália. Outros direitos foram assegurados, como a jornada diária de oito horas, os Institutos de Aposentadoria e Pensões para trabalhadores formais e servidores e a Consolidação das Leis do Trabalho (CLT).

${ }^{8}$ Tal situação demonstra uma concepção de direito social como privilégio, o que foi definido por Wanderley Guilherme dos Santos ${ }^{[5]}$ como "Cidadania Regulada", ou seja, uma cidadania limitada por restrições políticas: os benefícios atingiam aqueles a quem o governo decidia favorecer, de modo particular aos que se enquadravam na estrutura sindical corporativa mantida pelo Estado.

${ }^{9}$ É preciso notar que substancial contingente da população permaneceu fora do sistema de seguridade, a começar pelos trabalhadores rurais e suas famílias, que, em 1960, ainda representavam $55 \%$ da população, passando pelos autônomos e chegando às empregadas domésticas, muitas das quais vivendo sob semi-escravidão, além daqueles que operavam na informalidade, que constituíam expressiva massa desamparada.
} 
Vale ressaltar que, o processo de redemocratização brasileira tem como ponto de partida o ano de 1979, quando começa o processo de distensão, ou abertura "lenta e gradual" comandada pelo Presidente General Figueiredo, último presidente imposto pelo regime militar. Nesse processo de distensão de maneira gradual foram concedidos aos brasileiros alguns direitos civis e políticos, que implicaram na reestruturação das organizações sociais, associações populares, sindicatos e partidos políticos. O processo de mobilização social passou a ser mais vigoroso com a eleição de Tancredo Neves, resultando no fato de que essas forças fizeram valer seus direitos na nova Constituição Federal. Além da garantia de direitos civis e políticos, a Constituição garantiu, por força das mobilizações sociais, ampliação dos direitos sociais. Isto significou a incorporação das parcelas mais pobres da população brasileira aos direitos sociais, mesmo não contribuindo diretamente para o recebimento de benefícios (como aposentadoria, proteção à saúde e educação).

A partir de 1989, os direitos instituídos na Constituição passaram a significar possibilidades de acesso a uma vida digna a todos os brasileiros. A exigência de que esses direitos deveriam ser garantidos pelo Estado significou, também, que deveriam ser financiados não só pelo mercado de trabalho formal (trabalhadores e empresários - via folha de pagamento), mas com recursos do tesouro, portanto, de toda a sociedade. Tal fato aponta para uma transição no Brasil, de um Estado de bem estar corporativo-particularista, para um Estado de bem estar institucional-redistributivo, abrindo caminho para assegurar a todos os cidadãos brasileiros, independentemente de sua contribuição/inserção no mercado de trabalho, benefícios sociais financiados coletivamente, quando, por questões alheias à sua vontade, não tenham condições de se sustentarem dignamente. Assim, deve ser assegurado a todos, como direito: a garantia de amparo na velhice, na invalidez, na maternidade, no desemprego, no acidente de trabalho, entre outros direitos sociais.

Nessa mesma linha, o direito à alimentação é um dos frutos do processo democrático brasileiro. No período de mobilização para impedimento do Presidente Fernando Collor, por corrupção, movimentos sociais, em sua maioria, ligados ao Partido dos Trabalhadores (PT), iniciaram uma grande movimentação em defesa da "vida e contra a fome", que refletiu no programa de governo do partido, que nele incluiu o Programa Fome Zero. Nesse processo, o direito à alimentação foi assegurado na Constituição de 1988 e por uma lei específica. Esse processo de construção da cidadania alimentar passa-se a descrever a seguir.

\section{A POLÍtTICA PÚBLICA DE SEGURANÇA ALIMENTAR E SUA EVOLUÇÃO NO BRASIL: DE BEM ESTRATÉGICO PARA UM DIREITO SOCIAL}

Esta seção busca evidenciar, em primeiro lugar, a evolução e os fundamentos do conceito de Segurança Alimentar (SA), sob a perspectiva espaçotemporal de seus desdobramentos para se tornar um direito social. Em seguida, será elaborado um breve histórico de sua evolução no Brasil, até sua visão mais atual, como um direito social, garantido e instituído legalmente.

O conceito de Segurança Alimentar surgiu e tem se transformado desde a Segunda Grande Guerra Mundial. Sua formulação original desenvolveu-se sob o ponto de vista da soberania nacional ou de soberania alimentar, ao se referir à disponibilidade interna de alimentos para o abastecimento das forças armadas e da população dos países em conflito. Os países cujas reservas alimentares para o mercado interno e para sustentar suas tropas fossem insuficientes teriam piores condições de enfrentar conflitos internacionais. "Entendia-se, assim, a Segurança Alimentar como uma condição estratégica para a eventualidade de guerras" $[6](\mathrm{p} .12)$.

Posteriormente, em meados da década de 1970, a queda na produção de grãos na Europa e no Centro-Oeste Asiático, com a diminuição consequente da disponibilidade de alimentos, acompanhada de rápida elevação de preços, gerou pandemias de fome e graves crises sociais.

Tal fato despertou a atenção de autoridades internacionais que, reunidas em 1974, em Roma, naquela que foi a Primeira Conferência Mundial de Alimentos, acordaram que deveria ser prioritária a questão da segurança alimentar da população humana, a qual deveria se colocar acima das decisões de mercado ou do livre comércio internacional ${ }^{[6]}$.

Essa Conferência, realizada durante a crise de desabastecimento de alimentos, propôs que os países aumentassem sua produção e criassem estoques para situações emergenciais. Nessa época, o conceito de SA ainda estava distante da questão dos direitos humanos, estando mais ligado à questão do aumento da produção e da disponibilidade interna de alimentos ${ }^{[7]}$. 
O aumento global da produção de alimentos, ocorrido a partir da segunda metade da década de 1970, com a "Revolução Verde ${ }^{10 ", ~ n a ̃ o ~ s i g n i f i c a v a ~ o ~}$ atendimento da necessidade de consumo das grandes massas humanas. Os países em desenvolvimento, principalmente, conviviam com o aumento per capita da oferta, mas, ao mesmo tempo, continuavam a sofrer com graves problemas relativos à fome e à restrição alimentar da população de baixa renda. Verificavam-se, também, grandes estoques de alimentos nos países mais desenvolvidos e, ao mesmo tempo, crises de desabastecimento e fome em países mais pobres e menos desenvolvidos.

O aumento expressivo da produção e da produtividade na agricultura ocorria também nos países subdesenvolvidos, a partir da difusão da "Revolução Verde", o que não significava, contudo, que esses alimentos chegassem a todos os potenciais consumidores. Batista Filho[ ${ }^{[6]}$ observou que a disponibilidade de alimentos, em escala macroeconômica, não seria suficiente para se transformar em consumo efetivo, já que grandes contingentes humanos ficavam, parcial ou totalmente, fora do mercado de alimentos por insuficiência de renda. Tal fato significava "um obstáculo estrutural para o acesso regular (grifo nosso) aos alimentos necessários à nutrição humana, atendendo aos requisitos de suficiência, equilíbrio e adequação fisiológica e cultural’[6](p.13).

A garantia de acesso regular aos alimentos, pela acepção mais atual do conceito de Cidadania Alimentar ou SA, é dada pelo enfoque de um direito social, do indivíduo e da família. Esta perspectiva tem sido rediscutida numa série de eventos e conferências nacionais e internacionais. Sua difusão tem se dado internacionalmente pela Organização das Nações Unidas para a Agricultura e Alimentação (FAO) - basicamente a partir da Conferência de Roma, em 1974.

Desde o pós segunda guerra, o direito humano à alimentação foi colocado como um requisito básico ao próprio direito à vida, numa série de acordos internacionais, protagonizados por 200 nações ${ }^{[6]}$. Batista Filho ${ }^{[6]}$ cita explicitamente os seguintes:

1948 - Declaração Universal dos Direitos Humanos

\section{6 - Pacto dos Direitos Civis e Políticos}

1966 - Pacto dos Direitos Econômicos Sociais e Culturais

1979 - Pacto da Eliminação de Todas as Formas de Discriminação Contra as Mulheres

1996 - Conferência Humana dos Direitos Humanos ${ }^{[6](p .11)}$

Em 1996, realizou-se, em Roma, a Cúpula Mundial de Alimentação, com chefes de Estado e de governo, que reafirmaram o direito humano à alimentação, objetivando, até 2015, reduzir em 50\% o número de pessoas que padeciam de desnutrição crônica - calculada em cerca de 840 milhões. Como decorrência desse acordo, foi desenvolvido e aprovado, também em Roma, em 2004, pela 127 a Sessão do Conselho da FAO, um documento com orientações práticas para os países implementarem a realização progressiva do direito à alimentação adequada no contexto nacional[9].

\section{A questão da alimentação e da Segurança alimentar no Brasil}

No Brasil, mesmo que a desnutrição e a fome tenham sido sempre um grave problema social, somente na década de 1940 a questão da SA foi tratada de maneira mais sistemática, no trabalho pioneiro de Josué de Castro, "A Geografia da Fome - O Dilema Brasileiro: Pão ou Aço" ${ }^{[10]}$. Em seu livro, de 1946, declarava que a questão da fome no Brasil manifestava-se como epidemia e endemia.

Como epidemia, a fome se manifesta em seus aspectos locais e transitórios, como acontece nos períodos de seca do semiárido brasileiro e, como uma endemia, a fome é uma manifestação permanente de carências alimentares, consequência, sobretudo, de insuficiência de renda em camadas relevantes da população brasileira.

Em sua visão, defendia que o direito à alimentação deveria ser alvo de políticas de Estado e visto como um princípio que deveria sobrepor-se aos desígnios do desenvolvimento nacional: "O que é necessário por parte dos poderes públicos é condicionar o desenvolvimento e orientá-lo para fins bem definidos, dos quais nenhum se sobrepõe ao da alimentação do povo"[10][(p. 291-2).

\footnotetext{
${ }^{10}$ A "Revolução Verde" é uma iniciativa de organismos internacionais de fomento ao desenvolvimento, como o Banco Mundial, e instituições de pesquisas ligadas a grandes empresas de agribusiness, que deram apoio tecnológico e financeiro à produção de alimentos, principalmente de grãos, nos países mais pobres. Houve estimulo para o uso intensivo de insumos e defensivos químicos, assim como de máquinas e equipamentos, para operar em larga escala. Verificou-se um aumento expressivo na produção nesta base tecnológica favorecida por grandes áreas com monoculturas, o que significou graves efeitos no meio-ambiente sem, contudo, diminuir a desnutriç̃o e a fome. A questão de insegurança alimentar, nos países pobres, estava ligada à acessibilidade aos alimentos, ou seja, à insuficiência estrutural de renda de grandes parcelas da população[ ${ }^{[8]}$,
} 
Mesmo com o alerta de Josué de Castro, pioneiro na questão da discussão da fome no cenário internacional, no Brasil, as iniciativas dos poderes públicos só se faziam presentes quando a questão da fome apresentava aspectos mais graves, como epidemia, principalmente nas áreas intermitentemente assoladas pela seca do semiárido nordestino.

Fora dessas quadras de fome epidêmica, o poder público não se fazia presente como provedor do direito à alimentação em escala necessária. Verificaram-se, entretanto, algumas iniciativas pontuais e emergenciais de garantia de acesso alimentar para públicos específicos. A questão da SA, no Brasil, era vista e tratada pelo poder público, ora sob o prisma da agricultura e do abastecimento alimentar (produção, distribuição, controle de preços e de estoques), ora como ações emergenciais de distribuição de alimentos em situações de crises de abastecimento (determinadas por fenômenos naturais ou graves crises sociais) ou, ainda, como ações governamentais de cunho corporativista, errático ou clientelista ${ }^{[11]}$.

Pode-se fazer uma reconstituição do histórico dessas ações ou programas de SA por meio de um recorte temporário, sugerido por Vasconcelos ${ }^{[12]}$, relacionado a contextos específicos em que ocorreram iniciativas governamentais relativas à alimentação e à nutrição no Brasil.

\section{As primeiras ações nacionais de Segurança alimentar no Brasil (1930 - 1963)}

De acordo com Vasconcelos ${ }^{[12]}$, os primeiros programas nacionais de SA no Brasil surgiram durante a Ditadura Vargas (1937 a 1945), delineados por influência dos trabalhos de Josué de Castro que vinham sendo publicados em Recife desde 1932. São desse período, também, os primeiros cursos de Nutrição no Brasil, assim como a preocupação em se basear o cálculo dos salários, por lei específica, no valor da alimentação necessária à "reprodução da força de trabalho" dos trabalhadores.

Vasconcelos ${ }^{[12]}$ cita, também, a criação, em 1940, do Serviço de Alimentação da Previdência Social (SAPS) e, em 1945, da Comissão Nacional de Alimentação (CNA). O SAPS, que funcionou até 1967, possibilitou a criação de restaurantes populares e supermercados voltados para o atendimento de categorias profissionais, dentro do sistema corporativo vigente, principalmente para os segurados dos Institutos e Caixas de Aposentadorias e Pensões. A CNA, extinta em 1972, foi criada para propor normas para as políticas nacionais de alimentação e promover pesquisas relativas à questão nutricional da população brasileira. Essa comissão possibilitou a formulação de fundamentos e subsídios, empíricos e teóricos, para o Primeiro Plano Nacional de Alimentação e Nutrição, lançado em 1953 (alimentação materno-infantil) e criou as bases para o Programa Nacional de Alimentação Escolar (PNAE), institucionalizado em 1954, e que veio a ser o maior programa público brasileiro de alimentação.

Os planos pós primeiro governo de Vargas, como o SALTE (Saúde, Alimentação, Transporte e Energia) do governo Dutra, os programas de alimentação do segundo governo Vargas e o Plano de Metas de Juscelino Kubitschek não avançaram além do marco das ações do SAPS.

\section{O período da Ditadura Militar (1964 - 1985)}

O período da ditadura militar caracterizou-se pelo crescimento acelerado da economia, sem uma correspondente preocupação com os seus efeitos, principalmente com o crescimento desordenado da urbanização, cuja consequência se fez sentir no aumento da pobreza no campo e na cidade. O aumento absoluto da desnutrição era apontado em estudos relativos ao consumo doméstico e ao orçamento familiar.
A degradação das condições de vida das massas trabalhadoras excluídas do processo de crescimento econômico foi atestada por vários estudos. Em 1974/1975 o Estudo Nacional das Despesas Familiares (ENDEF) atestava que $67 \%$ da população apresentava um consumo energético inferior às necessidades mínimas recomendadas pela Organização Mundial de Saúde - OMS ${ }^{[12](p .5)}$.

Dentro do contexto da crise mundial de alimentos da década de 1970, os governos militares voltaram sua atenção para a garantia de suprimento desses produtos nas grandes cidades, objetivando seu abastecimento e, ao mesmo tempo, a prevençãocontra distúrbios sociais que pudessem decorrer de crises de desabastecimento. Com efeito, nesse período, as ações de SA eram analisadas pelo ângulo da oferta de alimentos, como disponibilidade de estoques dentro da chancela da política agrícola. Nessa direção, foram criadas, em meados dessa 
década e sob a coordenação do Ministério da Agricultura, as Centrais de Abastecimento (CEASAs), com representações regionalizadas nos estados, demonstrando a preocupação dos governos militares com a questão da regularidade no suprimento de alimentos.

Os Planos Nacionais de Desenvolvimento (PND I e II) dos governos militares, que programavam metas econômicas e sociais, incorporaram orientações dos organismos internacionais com respeito à questão da alimentação e da nutrição. Nesse contexto, foi criado em 1972, sob a chancela do Ministério da Saúde, o Instituto Nacional de Alimentação e Nutrição (INAN) que, em 1973, instituiu o Programa Nacional de Alimentação e Nutrição I, relançado em 1976 com o nome de Programa Nacional de Alimentação e Nutrição II. Esses programas buscavam desenvolver ações de suplementação alimentar voltadas às populações carentes e em situação de risco alimentar (gestantes, nutrizes e crianças), estudantes e trabalhadores de baixa renda. Data desse período a instituição dos seguintes programas: (a) Programa de Nutrição e Saúde em parceria com as Secretarias Estaduais de Saúde; (b) Programa de Complementação Alimentar (PCA), por intermédio da Legião Brasileira de Assistência (LBA); (c) o Programa de Alimentação dos Trabalhadores (PAT), desenvolvido pelo Ministério do Trabalho, por meio do Departamento Nacional de Saúde e Segurança do Trabalhador, em parceria com empresários e trabalhadores; e (d) o Programa de Alimentos Básicos em Áreas de Baixa Renda (PROAB) ${ }^{[12]}$.

De acordo com Pessanha ${ }^{[11]}$, na verdade, somente na década de 1980 as ações do INAN tomaram corpo, por meio dos Programas: (a) Prevenção e Combate a Carências Nutricionais Específicas; (b) Programa de Suplementação Alimentar (PSA); e (c) Programa Nacional de Incentivo ao Aleitamento Materno (PNIAM). Em que pese uma orientação das ações, voltadas às camadas realmente necessitadas, avaliou-se à época que somente $10 \%$ dos recursos investidos atingiram seu público-alvo.

\section{Da Nova República ao Programa Fome Zero e a Constituição da Cidadania Alimentar}

O governo do Presidente José Sarney, foi o primeiro governo civil do período de redemocratização, que passou a ser conhecido como Nova República, logo após o fim dos governos militares. $\mathrm{Na}$ gestão Sarney, foram desenvolvidas algumas ações voltadas para a acessibilidade de alimentos por públicos específicos, como a reformulação do Programa Nacional de Alimentação Escolar (PNAE) da era Vargas e a implantação do Programa Nacional do Leite para Crianças Carentes (PNLCC, ticket-leite), vinculado à Secretaria Especial de Ação Comunitária, ligada diretamente à Presidência da República. Esse último recebeu pesadas críticas pelo formato clientelista da distribuição dos cartões e pelo fato destes, usados como moeda corrente, serem desviados pelos beneficiários para outras finalidades. O PNLCC foi a principal inovação da Nova República, já que foram mantidos os programas criados por intermédio do INAN, como o PNAE ${ }^{[12]}$.

Mesmo com o quadro recessivo do final da década de 1980 e início da década de 1990, a questão da SA, de forma mais ampla, foi relegada a um segundo plano pelo governo federal. Tratava-se a questão da alimentação por meio de programas específicos, ou preocupava-se mais com a disponibilidade de produtos e o aumento da produtividade agrícola, sem se atentar para a questão do acesso alimentar de grandes contingentes de população urbana cuja renda era insuficiente para se alimentar de maneira adequada.

Em um ambiente de ampliação dos direitos civis e políticos e face às demandas sociais, alguns municípios do estado de São Paulo e do Paraná iniciaram programas pioneiros na área do abastecimento alimentar, enfocando a questão pelo lado do acesso ao alimento. O governo do estado de São Paulo lançou, no início da década de 1980, o Programa Paulista de Alimentação e Nutrição $(\text { PROPAN })^{11}$, que buscava envolver todos os municípios paulistas. A iniciativa teve poucos resultados práticos por falta de integração entre os programas do governo do estado e o nível federal, de uma maior articulação intermunicipal e por dificuldades políticas e burocráticas, além da falta de organização dos pequenos produtores e de comerciantes varejistas e de mobilização dos consumidores de baixa renda ${ }^{[13]}$. 
No governo Collor, vários programas sociais do governo federal foram extintos ou reformulados, devido às críticas à ineficiência e às irregularidades encontradas pelo Tribunal de Contas da União (TCU), principalmente nos programas PNAE, PSA, PCA e PNLCC. Os programas de suplementação e de complementação alimentar deram lugar aos programas "Minha Gente" e "Gente da Gente", que distribuíam cestas básicas e, em 1993, serviriam de apoio para a implantação e a implementação do Programa de Distribuição Emergencial de Alimentos (PRODEA).

Destaca-se, no ano de 1990, a criação, no âmbito do Ministério da Saúde, do Sistema Nacional de Vigilância Alimentar e Nutricional (SISVAN), com o objetivo de diagnosticar os problemas relativos à alimentação, assim como apontar ações a serem desenvolvidas no sentido de sua resolução.

Observe-se que a Segurança Alimentar não fora ainda tratada, no Brasil, pela perspectiva do direito, pelo menos até o governo Collor, mesmo que houvesse, em anos anteriores, preocupação e mobilização de profissionais da área da saúde com a questão da alimentação e da nutrição - evidenciada pela realização, em 1985, da I Conferência Nacional de Alimentação e Nutrição (I CNAN), como desdobramento da $8 \underline{\underline{a}}$ Conferência Nacional de Saúde ${ }^{[7,12]}$.

Foi na I CNAN que a interpretação do conceito de SA foi direcionada mais para a questão do acesso aos alimentos do que para o enfoque estrito do abastecimento. Nesta conferência foi incorporado ao conceito de SA o termo "nutricional", destacando o aspecto biológico/nutricional da alimentação, uma contribuição do movimento sanitarista sem, contudo, enfocá-lo como um direito:

\footnotetext{
O conceito de Segurança Alimentar que, anteriormente, era limitado ao abastecimento, na quantidade apropriada, foi ampliado, incorporando também a questão do acesso universal aos alimentos, o aspecto nutricional e, consequentemente, as questões relativas à composição, à qualidade, e ao aproveitamento biológico. O Brasil adotou este novo conceito a partir de 1985, com a I Conferência
}

\begin{abstract}
Nacional de Alimentação e Nutrição, o qual consolidou-se quando da I Conferência Nacional de Segurança Alimentar, em 1994[14](p.11).
\end{abstract}

"As primeiras referências à expressão Segurança Alimentar surgem no Ministério da Agricultura"'[7](p.16), mas focando-a na questão da produção agrícola e do abastecimento. Já a questão da SA, sob o enfoque de um direito social básico, só seria incluída na agenda nacional no ano de 1991, na proposição de uma Política Nacional de Segurança Alimentar feita pelo Partido dos Trabalhadores.

O documento "Política Nacional de Segurança Alimentar" do PT apresenta a questão da SA, ligada aos movimentos sociais, dentro da arena política, como um direito social. A SA foi citada como direito, por meio do "Governo Paralelo", uma estratégia da oposição, notadamente do P'T, ao governo Collor, para criticar as ações do governo e trazer contribuições ao debate nacional.

$$
\begin{aligned}
& \text { [...]inserindo-a na luta político- } \\
& \text { partidária e na disputa pelo } \\
& \text { conteúdo das políticas públicas } \\
& \text { voltadas para o setor agroalimentar, } \\
& \text { abarcando questões relativas à } \\
& \text { defesa dos direitos da cidadania e à } \\
& \text { democracia social, razão por que } \\
& \text { pode ser considerada como um } \\
& \text { marco na difusão do tema no país. } \\
& \text { O documento toma a alimentação } \\
& \text { como um direito elementar do } \\
& \text { cidadão e ressalta a necessidade de } \\
& \text { respostas urgentes à magnitude do } \\
& \text { problema da miséria e da } \\
& \text { fome }{ }^{[1](p .12-3)} \text {. }
\end{aligned}
$$

Ainda que o governo Collor não tenha tomado nenhuma iniciativa em relação às propostas do "Governo Paralelo", o processo de seu impedimento, capitaneado pela sociedade civil, possibilitou a criação do Movimento pela Ética na Política. Esse Movimento deflagrou a "Ação da Cidadania contra a Fome, a Miséria e pela Vida", que viria a desempenhar importante papel na mobilização de um grande conjunto de organizações sociais em torno da questão do direito ao alimento. As campanhas tinham como liderança e símbolo o Sociólogo Herbert de Souza - "Betinho"[11]12, que voltara do exílio em 1979.

\footnotetext{
${ }^{12}$ Por meio da Ação da Cidadania, foram constituídos mais de cinco mil comitês no Brasil que tinham duas tarefas básicas: ações emergenciais (coleta e distribuição de alimentos a famílias carentes) e ações de pressão de opinião pública em torno da ética, contra a pobreza e a fome $\mathrm{e}^{[11](p .9)}$.
} 
Com o impedimento de Collor, assumiu a presidência o vice-presidente Itamar Franco, que adotou, já em 1993, algumas das teses do documento Programa Nacional de Segurança Alimentar do "Governo Paralelo". Tal fato possibilitou a criação de três instrumentos que se constituíram em um marco na história da SA no Brasil:

a) O "Mapa da Fome" do IPEA, de 1993, que revelou a dimensão do problema da fome ao país;

b) $\mathrm{O}$ "Plano de Combate à Fome e à Miséria", que indicou um conjunto articulado de compromissos de ação de governo, marcado por três princípios: parceria, solidariedade e descentralização;

c) A criação do Conselho Nacional de Segurança Alimentar (CONSEA), que tinha caráter consultivo e de assessoria à Presidência da República, formado por Ministros de Estado e conselheiros indicados da sociedade civil por intermédio do Movimento pela Ética na Política.

O CONSEA organizou, em 1994, a I Conferência Nacional de Segurança Alimentar (ICNSA), quando incorporou ao conceito de SA a expressão nutricional, como já ressaltado anteriormente. Um grande avanço dessa Conferência foi uma percepção da necessidade de parcerias entre Estado, movimentos sociais e iniciativa privada na questão do combate à fome. Deve-se ressaltar aqui, como sugere Tartaglia ${ }^{[15]}$, que a alimentação ou a SA deve ser vista como um bem público:

Trata-se, portanto, de um bem público cuja provisão não é assegurada pelo livre funcionamento do mercado, dado o caráter privado da produção e da comercialização de alimentos. A obtenção e manutenção da Segurança Alimentar é um objetivo estratégico e supõe responsabilidade pública, envolvendo Estado e Sociedade. Exige a articulação convergente de

$$
\begin{aligned}
& \text { múltiplas políticas e } \text { ações com } \\
& \text { participação e e } \\
& \text { social.[15](p.156) }
\end{aligned}
$$

Mesmo com as ações da sociedade civil e o comprometimento do Governo Federal, ademais de mecanismos de participação e controle social possibilitado pelo CONSEA, as ações voltadas para a SA não poderiam implicar em melhorias notáveis no governo Itamar Franco, pelo fato de serem ainda incipientes, tendo sido implementadas em um período que se resumiu aos dois anos em que Franco sucedeu Collor de Mello. Deve-se, todavia, ressaltar os três instrumentos anteriormente apontados (Mapa da Fome, Plano de Combate à Fome e CONSEA e I CNSA) como importantes avanços para a questão no Brasil ${ }^{13}$.

O governo subsequente, Fernando Henrique Cardoso - FHC extinguiu o CONSEA e o incipiente Plano de Combate à Fome e à Miséria. Instituiu o Programa Comunidade Solidária, conforme Decreto 1366, de 12.01.1995, com o objetivo explícito de combate à fome e à pobreza, o qual criticava os programas sociais dos governos anteriores, principalmente os que enfocavam a questão da desnutrição, taxando-os de assistencialistas e clientelistas. $\mathrm{O}$ Comunidade Solidária deslocou o foco da questão da fome, ou da SAN, para a questão da pobreza ${ }^{14}$. Implementou ações focalizadas e descentralizadas em vários órgãos, em que se fizeram presentes programas de renda mínima (Bolsa Alimentação, Bolsa Escola, Vale Gás) para populações específicas.

Pessanha ${ }^{[11]}$ observou que os mesmos "velhos aspectos" dos programas do governo Itamar Franco e dos anteriores, criticados pelo governo FHC, foram percebidos, também, na gestão do Programa Comunidade Solidária. Considerou-se que os recursos foram apropriados "para a geração de dividendos político-eleitorais, passando a atender ao clientelismo assistencialista dos gestores no âmbito local"[11](p.23).

Em 1999, o Ministério da Saúde lançou o Plano Nacional de Alimentação e Nutrição, no qual é defendida a questão da alimentação como um direito, pelo enfoque setorial da saúde ${ }^{[14]}$.

\footnotetext{
${ }^{14}$ Dedecca e Barbiere ${ }^{[16]}$ não veem uma identidade imediata entre fome, pobreza e SA, como propõe o Comunidade Solidária. Para eles, citando Monteiro (2003): “[...] fome, desnutrição e pobreza são problemas de natureza distinta no país e, mais importante, que comportam soluções distintas, ainda que compartilhando causas e vítimas. Dos três problemas, a pobreza talvez seja o mais fácil de definir. De modo bastante simples, pode-se dizer que a pobreza corresponde à não satisfação de necessidades humanas elementares como comida, abrigo, vestuário, educação, assistência à saúde, entre outras [...] Contabilizam-se como pobres as famílias cuja renda seja inferior à linha de pobreza. Quando a linha de pobreza se baseia apenas no custo da alimentação, fala-se de pobreza extrema, indigência ou mesmo insegurança alimentar. A desnutrição ou, mais correntemente, as deficiências nutricionais são decorrentes de aporte alimentar insuficiente em energia e nutrientes ou ainda inadequado aproveitamento biológico dos alimentos [...] A fome é certamente o problema mais difícil de definir [...] De modo mais prático, (sua aferição) é feita a partir da avaliação das reservas energéticas dos indivíduos, mais especificamente avaliando-se a relação entre seu peso e altura, admitindo-se que o potencial dos indivíduos com insuficiente relação peso/altura, emagrecidos portanto, expresse razoavelmente bem a magnitude da deficiência energética crônica ou da fome da população". [16](p.98) 
$\mathrm{O}$ enfoque mais ampliado da questão do direito básico à alimentação do conceito de SA foi retomado em outubro de 2001, com o lançamento do Projeto Fome Zero (PFZ), encomendado ao Instituto Cidadania - instituição de pesquisa ligada ao Partido dos Trabalhadores. O projeto procurava reunir sugestões para um programa nacional de combate à fome no Brasil, tendo como subtítulo: "Uma Proposta de Política de Segurança Alimentar Para o Brasil”. Elaborado por pesquisadores e especialistas, tinha a preocupação de combater a fome e diminuir os níveis de miséria no Brasil que afligiam, na época, cerca de 9,3 milhões de famílias com renda per capita inferior a um dólar por dia. Organizou-se uma série de ações para enfrentar o problema da fome, que iam desde ações emergenciais, de doações de alimentos e transferência de renda, até a geração de emprego e de renda, com papéis delineados para todos os entes federados e sociedade civil[17,18].

O presidente eleito em 2002, Luiz Inácio Lula da Silva, definiu que o combate à fome, à desnutrição e à miséria seria a principal meta social de seu governo. O Projeto Fome Zero (FZ) deveria transformar-se em política pública e programa de governo, sob a chancela de um Ministério, o que indicava a importância dispensada ao tema. Em discurso de posse no Congresso Nacional, o Presidente declarou:

[...] defini entre as prioridades de meu governo um programa de segurança alimentar que leva o nome de "Fome Zero". Como disse em meu primeiro pronunciamento após a eleição, se, ao final de meu mandato,todos os brasileiros tiverem a possibilidade de tomar café da manhã,almoçar e jantar, terei cumprido a missão de minha $\operatorname{vida}^{[12](p .11)}$.

Foi criado, no início do governo, o Ministério Extraordinário de Segurança Alimentar e Combate à Fome (MESA) para executar e coordenar um programa relativo ao combate à fome e que promovesse a SA. Depois de muitas críticas e dificuldades enfrentadas, o MESA foi reestruturado e, em seu lugar, criou-se o Ministério do Desenvolvimento Social e Combate à Fome (MDS). Esse Ministério recebeu, incorporando-as, ações (e recursos) de outras pastas ministeriais, principalmente aquelas delineadas por meio de programas de transferências de renda herdadas do governo anterior ${ }^{[18,19]}$.

Assim, em 2004, programas como o Vale Gás, o Bolsa Escola e o Bolsa Alimentação foram fundidos num só programa, o Bolsa Família, sob a coordenação do MDS. Foram criados outros programas e parcerias com outros Ministérios que tinham programas correlatos à questão da SA.

Em termos práticos o FZ, hoje, consiste em um conjunto de mais de 30 programas complementares direcionados a combater as causas imediatas e subjacentes da fome e $\mathrm{da}$ insegurança alimentar implementadas pelo ou com o apoio do Governo Federal[18](p.4).

Além da criação de ações governamentais na questão da desnutrição, o Governo Federal recriou, em 30 de janeiro de 2003, um mecanismo de articulação, controle social e participação dos movimentos sociais organizados, o Conselho Nacional de Segurança Alimentar e Nutricional (CONSEA), para assessorar a Presidência da República na formulação de políticas e dar orientações para que o País pudesse garantir a todos o direito humano à alimentação ${ }^{15}$.

O CONSEA vem mobilizando a sociedade e colocando a questão da SAN no cenário nacional. Coordenou e realizou em Olinda, em 2004, a II Conferência Nacional de Segurança Alimentar, quando o conceito de Segurança Alimentar foi definido como:

A realização do direito de todos ao acesso regular e permanente a alimentos de qualidade, em quantidade suficiente, sem comprometer o acesso a outras necessidades essenciais, tendo como base, práticas alimentares promotoras de saúde, que respeitem a diversidade cultural e que sejam social, econômica e ambientalmente sustentáveis ${ }^{[20](\mathrm{p} .4)}$.

Esse conceito foi objeto de amplos debates com a contribuição de acadêmicos, gestores públicos e dos movimentos sociais ligados à saúde e à agricultura e de vários fóruns da sociedade civil representativos da defesa da Segurança Alimentar. 
O direito à alimentação foi garantido como direito legal por lei federal sancionada pelo presidente Luiz Inácio Lula da Silva, em 15 de setembro de 2006, coroando o processo de mobilização da sociedade brasileira em torno da Segurança Alimentar, sob o título de Lei Orgânica de Segurança Alimentar e Nutricional (LOSAN) ${ }^{[21]}$.

O direito à alimentação, já assegurado na legislação infraconstitucional, foi reafirmado com mais força na Constituição de 1988. Passou a ser assegurado no Capítulo II de nossa lei maior, que dispõe sobre os Direitos Sociais dos brasileiros, por meio da Emenda Constitucional no 064/2010 que incluiu no Artigo $6^{0}$ da Constituição Federal o direito à alimentação entre os demais direitos já garantidos. O Artigo 6o ficou com a seguinte redação:

Art. 6o São direitos sociais a educação, a saúde, a alimentação, o trabalho, a moradia, o lazer, a segurança, a previdência social, a proteção à maternidade e à infância, a assistência aos desamparados, na forma desta Constituição.

O direito à alimentação adequada e suficiente para todos já pode, por meio da Constituição, ser considerado um direito social. Daí poder falar em cidadania alimentar. A mobilização para a conquista desse direito é fato recente no Brasil, remontando, como se viu, ao início da década de 1990. Mesmo em outros países, principalmente os mais desenvolvidos, essa questão não parecia estar na agenda política, pelo menos até o final das duas grandes guerras.

\section{CONSIDERAÇÕES FINAIS}

As políticas públicas trazem, junto com sua implementação, determinantes históricos, sociais e políticos (político aqui no sentido amplo da palavra "poder") que incluem alguns temas, ou não, na agenda pública. Tendo em vista esses determinantes, alguns problemas entram para a agenda das políticas públicas. As políticas públicas voltadas para a solução desses problemas que entraram para a agenda são instituídas por meio de leis e regulamentos e podem, portanto, serem entendidas como instituições que constroem benefícios e interesses. Uma vez instituídas, as políticas públicas estabelecem "regras de jogo" que funcionam como incentivos e constrangimentos às ações de diversos atores, criando padrões de comportamento, desenhando estruturas administrativas, criando práticas e rotinas que passam a influir com muita força na sua trajetória histórica.
Uma consequência da institucionalização que acaba influindo na sua continuidade é a formação de grupos de interesse e beneficiários interessados em sua manutenção. $O$ direito à alimentação não fazia parte do escopo da concepção da cidadania brasileira, a não ser a partir da Constituição Federal de 1988 e da LOSAN (2006), assim como da infraestrutura criada para torná-la efetiva. A partir dessa institucionalização os cidadãos podem se voltar para o Estado cobrando-lhe sua contribuição contratual legal e constituída no seu direito à alimentação. Abrem-se canais para pressões da sociedade, e, também, pela via dos tribunais, de maneira legal, jurídica, impositiva, para a efetivação material desse direito.

O direito à alimentação é um direito ainda em construção. São dez anos de mobilização social para sua efetivação, dez anos de implementação e execução do Fome Zero como programa de governo e sete anos de sua inscrição como componente da cidadania em nossa Carta Magna. Essa luta representa, talvez, um dos poucos direitos nascidos dos movimentos sociais que foi objeto de uma política pública nacional ampla e específica e, quase ao mesmo tempo, provida de uma garantia constitucional. Outros importantes direitos sociais, como os relativos ao trabalho, à previdência e à saúde, por exemplo, constituíram-se por meio de concessões feitas pelos governos no século XX. De maneira inversa, o direito à alimentação, à cidadania alimentar, foi uma conquista da sociedade, talvez como uma resposta à grande crise moral pela qual passava o Brasil no ano de 1992.

Organizações sociais envolvidas na mobilização pelo impedimento de Collor organizaram o Movimento pela Ética na Política, e partiram da constatação de que não era possível a convivência entre pobreza e democracia. Foi articulada a criação de milhares de comitês organizados em empresas e outras organizações em todo o Brasil, que promoveram uma grande mobilização nacional com shows e doações de alimentos, no sentido de chamar a atenção para os 32 milhões de brasileiros que estavam abaixo da linha de pobreza - não tinham recursos suficientes para sua subsistência.

As mobilizações sociais e a eleição do presidente Lula, tendo como uma das propostas o combate à fome, fizeram com que o tema entrasse com força na agenda política nacional, facilitando a determinação do presidente de transformar o Programa Fome Zero em uma meta principal de governo. 
No Brasil, o flagelo da insegurança alimentar esteve sempre presente na vida dos brasileiros, nem tanto por falta de alimentos, mas, sobretudo, por falta de condições de acesso, ou seja, de renda insuficiente para adquirir alimentos necessários à sobrevivência. Sendo um dos "campeões" de desigualdade social, que também é fruto e resquício do período escravocrata (do último país a libertar os escravos), é compreensível que a fome tenha sido uma constante na nossa história: seja como epidemia, nas situações de crises econômicas (que criam desemprego e desalento) e catástrofes naturais (chuvas excessivas e, principalmente, a seca); seja como endemia, como enfermidade crônica que afeta grandes contingentes de nossa população, sujeita a baixos salários e precários serviços de assistência.

O reconhecimento do direito à alimentação pela Constituição Federal; posteriormente, a promulgação da LOSAN; e as ações programáticas desenvolvidas no MDS deram visibilidade aos programas que vêm sendo executados por esse Ministério, garantindo-lhe apoio.

Como reflexo dessa formalização foi gerado um aparato institucional - normativo e organizacional, voltado à implementação de programas de governo que possibilitam o atendimento de um espectro relevante da população brasileira ainda não efetivamente atendida pelas ações públicas (populações abaixo da linha de pobreza, agricultores familiares de baixa renda, povos e comunidades tradicionais).

Pode-se constatar, por meio de indicadores, se esse aparato edificado para combater a pobreza e a fome tem sido efetivo. Vejamos um desses indicadores, relativo à situação da segurança alimentar no Brasil, que foi calculado e medido nos anos de 2004 e 2010, em um suplemento sobre SA da "Pesquisa Nacional de Amostra de Domicílios"16.

Os indicadores construídos buscaram captar a percepção dos entrevistados quanto a sua preocupação e angústia frente à possibilidade de não dispor de alimentos regularmente num futuro próximo e também o comprometimento tanto da qualidade, quanto da quantidade da alimentação necessária para o consumo, por não haver dinheiro suficiente para adquiri-los. Da mesma forma a pesquisa propôs avaliar o sentimento de insegurança alimentar dos entrevistados, de forma a fazer uma gradação em relação à sua segurança de obter e consumir alimentos. Ao detectar e dimensionar a insegurança alimentar no país, a metodologia da pesquisa permite classificar as unidades domiciliares (famílias) em duas modalidades: (a) domićlios em situação de Segurança Alimentar (SA); e (b) domicílios em Insegurança Alimentar (IA).

$\mathrm{Na}$ Tabela 1 podemos observar que a segurança alimentar da população brasileira aumentou de 60,1\% em 2004, para 65,8\% em 2009. Observa-se também, quando desagregamos por cor da pele e situação de domicílio, que a situação de segurança aumentou mais que proporcionalmente para pretos e pardos e para a população rural, certamente grupos mais afetados pelas condições de pobreza.

Tabela: Distribuição da população residente, por situação de segurança e insegurança alimentar segundo a cor ou raça, e situação do domicílio. Brasil - 2004-2009.

\begin{tabular}{lccccc}
\hline Referência & & \multicolumn{2}{c}{ Com Segurança Alimentar } & \multicolumn{2}{c}{ Com Insegurança Alimentar } \\
\hline Total & Total & $\mathbf{2 0 0 4}$ & $\mathbf{2 0 0 9}$ & $\mathbf{2 0 0 4}$ & $\mathbf{2 0 0 9}$ \\
Cor ou raça & $\mathbf{1 0 0 , 0}$ & $\mathbf{6 0 , 1}$ & $\mathbf{6 5 , 8}$ & $\mathbf{3 9 , 8}$ & $\mathbf{3 4 , 2}$ \\
Branca & & & & & \\
Preta e Parda & 100,0 & 71,8 & 75,4 & 28,2 & 24,6 \\
Amarela ou Indígena & 100,0 & $\mathbf{4 7 , 6}$ & $\mathbf{5 6 , 6}$ & 52,4 & 43,4 \\
Situação do domicilio & 100,0 & $\mathbf{7 3 , 0}$ & 77,5 & 27,0 & 22,5 \\
Urbana & & & & & \\
Rural & 100,0 & $\mathbf{6 2 , 2}$ & 67,0 & 37,7 & 33,0 \\
\hline
\end{tabular}

Fonte: IBGE, 2010.

\footnotetext{
${ }^{16}$ A pesquisa permite mensurar diretamente o fenômeno de insegurança alimentar, de maneira qualitativa e quantitativa e capturar não apenas as dimensões físicas, mas também as dimensões psicológicas das condições de privação de alimentos. A metodologia destas pesquisas envolve Escalas de Percepção Insegurança Alimentar. No Brasil o IBGE aplicou esta pesquisa nos anos de 2004 e 2010, num suplemento da PNAD (Pesquisa Nacional de Amostra por Domicílios). As pesquisas de percepção sobre o estado ou expectativa de segurança alimentar (SA) ou IA procuram captar situações de privação alimentar, bem como de insegurança decorrente do temor de privações futuras para obtenção de alimentos em quantidade ou qualidade suficiente para sua família.
}

Segurança Alimentar e Nutricional, Campinas, 22(2):692-705, 2015 
A situação com relação à pobreza também melhorou, sendo uma das causas do aumento da SA. Por essa mesma pesquisa, verificou-se que a pobreza no Brasil diminuiu 50,64\% entre dezembro de 2002 e dezembro de $2010^{17}$, período de implementação do Programa Fome Zero. Os dados da pesquisa mostram melhoria da distribuição de renda para os $50 \%$ mais pobres que aumentou em $67,93 \%$ no período, ao passo que a renda dos $10 \%$ mais ricos cresceu $10 \%$.

Ainda que a situação da SA e dos indicadores de pobreza tenham melhorado, fruto de mudanças graduais nas políticas sociais, do crescimento econômico e da estabilidade da moeda desde 1994 e, ainda, tenham ficado melhores com o avanço dos programas sociais implantados no governo Fernando Henrique Cardoso e Lula (principalmente os programas de transferência de renda), a segurança alimentar e a pobreza ainda são, em termos absolutos, os problemas que mais afligem a sociedade brasileira e impedem seus cidadãos de acesso a condições mínimas de bem estar.

Com efeito, dados do Cadastro Único para Programas Sociais do Governo Federal (CADÚnico), que é uma base de informações, que servem como critérios para identificar famílias em estado de pobreza (aquelas que sobrevivem com renda mensal igual ou inferior a $1 / 2$ salário mínimo ${ }^{18}$ ) identificaram, no ano de 2013, 23 milhões de famílias abaixo da linha de pobreza, o que significa perto de 78 milhões de pessoas. Mais da metade dessas famílias estão recebendo benefícios dos programas de transferência de renda do Governo Federal (grande parte deles implementados pelo Programa Fome Zero), o que é um bom grau de cobertura.

Pelos dados da Pesquisa Nacional por Amostra de Domicílios (PNAD) ${ }^{[2]}$ de 2010, verificou-se que, no país, ainda existiam cerca de 16 milhões de pessoas em situação de extrema pobreza (que não tem renda suficiente para manter uma dieta alimentar suficiente para sua subsistência). Isto é quase o tamanho populacional do Chile ou de um Portugal e meio. Tomando por base o Censo de 1990, pode-se dizer que a pobreza extrema também diminuiu pela metade, tendo como fatores determinantes as seguintes: estabilidade de preços, crescimento econômico e programas sociais que foram sendo implementados a partir de 1993, pelos governos Fernando Henrique Cardoso e Lula.

A amplitude, gravidade e profundidade da questão da pobreza são fatores que nos perseguem por séculos e que vêm afetando o bem estar dos brasileiros. Debelar essa situação e garantir o direito primeiro e fundamental da alimentação, ao mesmo tempo em que são garantidos outros direitos sociais básicos é um desafio para as atuais e futuras gerações.

O Brasil carrega o peso advindo do sistema escravocrata e de falta de ações de garantia de condições de vida dignas para todos os brasileiros em sua trajetória histórica e parece fadado a enfrentar, por muito tempo, no dizer de Carvalho ${ }^{[23]}$, uma "cidadania inconclusa", que nos torna desiguais na renda recebida do trabalho; no acesso ao patrimônio; na cobertura e na qualidade de políticas públicas universais efetivas (saúde, educação, habitação); em fatores adscritos como a cor da pele; no direito aos benefícios das cidades, que segregam a maioria dos cidadãos brasileiros em favelas e moradias precárias; e no direito à alimentação suficiente, adequada e segura.

\section{Referências}

[1] Marshall TH. Cidadania, classe social e status. Rio de Janeiro: Zahar; 1967. 220 p.

[2] Pierson P. When effect becomes cause: policy feedback and political change. World Polit. 1993; 45 (4): 595-628.

[3] Pierson P. Dismantling the Walfare State? Reagan, Thatcher, and the politics of retrenchment. Cambridge: University Press; 1994. 224 p.

[4] Meny I, Thoening JC. Las Políticas Públicas. Barcelona: Editora Ariel; 1992. 271 p.

[5] Santos WG. Cidadania e justiça: a política social na ordem brasileira. 3 ed. Rio de Janeiro: Ed. Campus; 1994. $148 \mathrm{p}$.

[6] Batista Filho M. Sustentabilidade alimentar do semiárido brasileiro. Recife, Pernambuco: IMIP; 2005.72 p. (Série Publicações Científicas Instituto Materno Infantil Prof. Fernando Figueira - IMIP, 11).

[7] Instituto de Pesquisa Econômica Aplicada. Segurança alimentar e nutricional no Brasil. Brasília: IPEA; 1996. 57 p. (Cadernos Comunidade Solidária, 2)

[8] Cunha ARAA, Lemos MB. Segurança alimentar sob o prisma das políticas urbanas de abastecimento. Belo Horizonte: CEDEPLAR; 1996. (Texto para discussão, 113)

\footnotetext{
${ }^{17}$ Este indicador de pobreza é usado como critério pela Fundação Getúlio Vargas, que define linha de pobreza para pessoas que tenham renda insuficiente para se alimentar, vestir, locomover, educar-se, etc., ou seja, ter renda per capita abaixo de $R \$ 151,00, € 46,73$ ou US\$ 62,48 (cotação de 21/08/2013).

${ }^{18}$ O Salário Mínimo Nacional reajustado, a preços de hoje, é de R \$ 788,00 até janeiro de 2016 - ou US\$ 20, 46, cotação em 01/12/2015.
} 
[9] Food and Agriculture Organization of the United Nations (FAO). Diretrizes voluntárias: em apoio à realização progressiva do direito à alimentação adequada no contexto da segurança alimentar nacional. Roma: FAO; 2004. 42 p.

[10] Castro J. Geografia da fome: o dilema brasileiro: pão ou aço. Rio de Janeiro: Civilização Brasileira; 2005. 318 p.

[11] Pessanha LDRA. Experiência brasileira em políticas públicas para a garantia do direito ao alimento. Rio de Janeiro/RJ: IPEA; 2002. 67 p.

[12] Vasconcelos FAG. Combate à fome no Brasil: uma análise histórica de Vargas a Lula. Revista de Nutrição. 2005;.18 (4): 439-57.

[13] Gomes Júnior NN. Modelo de intervenção municipal em abastecimento alimentar. In: Anais da 21 $1^{\text {a }}$ Conferência Internacional do Instituto Cubano de Investigação e Orientação do Consumo e da Demanda Interna; 4-6 set 1991 Havana, Cuba: Instituto Cubano de Investigação e Orientação do Consumo e da Demanda Interna; 1991. p. 65.

[14] Ministério da Saúde. Política Nacional de Alimentação e Nutrição. Brasília: Ministério da Saúdo; 2003. 83 p.

[15] Tartaglia JC. Desenvolvimento, fome e segurança alimentar. In: Galeazzi MAM, organizador. Segurança alimentar e cidadania: a contribuição das universidades paulistas. São Paulo: Mercado de Letras; 1996. p. 117-30.

[16] Dedecca CS, Barbiere CV. Fome Zero e pilotos para a política social. Rev Econ Contemp. 2003; 9(1): 95-123.

[17] Instituto de Cidadania. Uma proposta de política de segurança alimentar para o Brasil. São Paulo: Instituto de Cidadania; 2001. 26 p.

[18] Belik W, Gross MDO. Programa Fome Zero no contexto das políticas sociais no Brasil. Cadernos de Debate. 2003:10;1-24.

[19] Organização das Nações Unidas para Alimentação e Agricultura. Fome Zero: lições principais. documento de trabalho: vídeo vonferência. Chile: FAO; 2006. 14 p.

[20] Conselho Nacional de Segurança Alimentar e Nutricional. Princípios e diretrizes de uma política nacional de segurança alimentar e nutricional: Textos de Referência da II Conferência Nacional de Segurança Alimentar e Nutricional. Brasília: CONSEA; 2004. 80 p.

[21] BRASIL Cria o Sistema de Segurança Alimentar e Nutricional - SISAN com vistas em assegurar o direito humano à alimentação adequada e dá outras providências. Lei Federal no 11.346, 14/09/2006. Brasília; 2006.
[22] Instituto Brasileiro de Geografia e Estatística. Pesquisa Nacional por Amostra de Domicílios: segurança alimentar (2004/2009).Brasília: IBGE; 2010. 183p.

[23] Carvalho JM. Cidadania no Brasil: o longo caminho. Rio de Janeiro: Civilização Brasileira; 2002. 236 p. 